\title{
A multidimensional model of healthy ageing: proposal and evaluation of determinants based on a population survey in Ecuador
}

\author{
María Fernanda Rivadeneira ${ }^{1 *}$, María José Mendieta ${ }^{2,3}$, Jessica Villavicencio ${ }^{4}$, José Caicedo-Gallardo ${ }^{1}$ and
} Patricio Buendía ${ }^{4}$

\begin{abstract}
Background: Healthy ageing is a complex construct which involves multiple dimensions. Previous studies of healthy ageing have focused only on measuring the intrinsic capacity of the older person. The objectives of this study were to design a multidimensional model of healthy ageing and to identify its determinants from national data in Ecuador.

Methods: A cross-sectional analytical study was carried out from the National Survey of Health and Well-being of the Older Adult, 2010. Sample was 1797 adults aged 65 years or more. A multidimensional model was designed based on the World Health Organization's concept of healthy ageing. For the analysis, two groups were created: a healthy ageing and a less healthy ageing group. Bivariate and multivariate logistic regressions were performed to analyze the probability of belonging to the healthy group according to sex, age, area of residence, level of education, perceived health status, perceived life satisfaction, and poverty by income level.

Results: The $53.15 \%$ of the sample was classified in the healthy ageing group. Women and the poorest older adults were less likely to be in the healthy ageing group (OR 0.58; 95\% Cl 0.464-0.737; OR 0.44; 95\% Cl 0.343-0.564). Older adults with secondary education or higher, who considered their health as excellent and who were satisfied with their life, had a greater probability of being in healthy ageing group (OR $2.61 ; 95 \% \mathrm{Cl} 1.586-4.309 ; \mathrm{OR} 28.49 ; 95 \% \mathrm{Cl}$ 3.623-224.02; OR 0.23; 95\% Cl 0.165-0.341).

Conclusions: This study contributes with a multidimensional approach to healthy ageing. It proposes to evaluate the intrinsic capacity of the individual, the social and political environment and the interaction with it, through indicators that discriminate who are ageing in a healthy way and who are not. By using this model, it was identified that gender and economic situation seem to play an important role on heathy ageing of the Ecuadorian population. Public policies are necessary to promote healthy ageing, especially focused on improving socioeconomic conditions and gender equity.
\end{abstract}

Keywords: Healthy ageing, Quantitative research methods, Multidimensional approach, Cross-sectional study

*Correspondence: mfrivadeneirag@puce.edu.ec

${ }^{1}$ Pontificia Universidad Católica del Ecuador, Facultad de Medicina, Instituto de Salud Pública, Quito, Ecuador

Full list of author information is available at the end of the article

\section{Background}

The ageing of the population represents a challenge for the health and social care systems. Globally, the number of people over 60 has increased alarmingly in the last 30 years and it is expected that by 2030 , they will exceed 
the number of children under the age of ten [1]. Multiple chronic conditions affect this population, impacting negatively in their quality of life and increasing their use of health and social care services [2]. Interventions aimed at preventing diseases and disabilities have proven to be cost-effective over time [3], so promoting healthy ageing in the population is appointed as the best strategy. However, until now there is no consensus around its conceptualization and how to measure it [4].

The efforts for associating a positive concept to the ageing process are not a recent endeavor. In the forty-fourth century BC, Cicero described ageing as a time of opportunities for positive change and productive functioning, while in the 1940s the use of the successful ageing concept was linked to the first attempts to develop indicators to determine the degree of satisfaction with life [5]. Later, Havighurst adopted it, describing the successful ageing as an adaptive theory and a testable experience [6]. But it was Rowe and Kahn [7] who popularized it to make a differentiation between "usual or normal" ageing from "successful" ageing. According to them, successful ageing encompasses older adults who have a low probability of disease and disability, high physical and cognitive capacity and an active commitment to life [7]. This conceptualization has been widely criticized and discarded for its restrictive approach [4-8].

Other attempts to describe the ageing process from a positive perspective have been done in Europe, by introducing the concept of active ageing [9]. "Active" was defined as a continuous participation in social, economic, cultural, spiritual and civic aspects and not only the ability to stay physically active or participate in the workforce [9]. But this model has not been validated either. Paúl, Ribeiro and Teixeira [10] demonstrated that most of the determinants of this model were not independent; while Bélanger and colleagues [11] concluded that the active ageing concept could be considered as a human rights policy orientation rather than an empirical measurement tool. Other authors have pointed out the risk of discrimination when idealizing the concept of active ageing, as a status that the entire older population should reach [9].

The healthy ageing term has been used at academic and political levels, to make a distinction between ill and not ill older adults, based mainly on their physical and mental attributes $[4,5]$. In the United States, McLaughling, Jette and Connell [12] identified a prevalence of healthy ageing ranging from 3.3 to $35.5 \%$. They used four operational definitions of healthy ageing based on the Rowe and Kahn definition of successful ageing. The authors highlighted that the large variation in the prevalence was the consequence of using rigid criteria, suggesting that greater importance should be given to the presence of symptomatic disease or the impact that it has on the functional status of the older person [12]. Similar results were found in a study of the Spanish population, with a prevalence of healthy ageing ranging from 4.5 to $49.2 \%$, depending on the criteria used to define it [4]. Recently, Dieteren and colleagues [13] published results of the ageing trajectories of a cohort of older adults, using the Healthy Ageing Index (HAI). The HAI predicts mortality, independently of the age or the presence of comorbidities, based on five physiological indicators. The authors highlighted the differences in the ageing trajectories, based on sex, nutrition and physical activity to achieve an optimal ageing [13].

In 2015, the World Health Organization (WHO) provided a more holistic definition of healthy ageing, defining it as "the process of promoting and maintaining functional capacity that allows well-being in old age." [14]. It is based on the interrelation between the intrinsic capacity of a person and their environment. Intrinsic capacity refers to all the mental and physical capacities that a person can rely on, including their ability to walk, think, see, hear, and remember. The environment includes interpersonal factors, such as the relationships that the older adult develops with other people and their participation in the community, contextual factors such as access to services, existing health and social policies, and the physical environment [14].

The aim of this study was to develop a multidimensional model of healthy ageing that incorporates measurements of the intrinsic capacity of the individual, the social and political environment, and the interaction with the environment. Additionally, we identified the determinants associated with healthy ageing, based on data from a national survey from Ecuador.

\section{Design and methods}

Analytical cross-sectional study with a secondary database from the National Survey of Health and Well-being of the Older Adult, 2010 (SABE, 2010).The SABE survey was carried out by the National Institute for Statistics and Census (INEC) and the Ministry of Economic and Social Inclusion (MIES) to identify the health and nutrition conditions of people over 65 years in Ecuador. The sample was random, probabilistic, and three-staged, proportional to the size of the population [15]. It was representative for the population over the age of 65 , according to the 2010 Census of INEC. The sample was limited to 1797 observations, corresponding to 898,152 adults aged 65 and over, after applying the expansion factor -suggested by the INEC to expand the sample to population size in 2010-. Survey data is available online at: https:// anda.inec.gob.ec/anda/index.php/catalog/292 [16]. 


\section{Components and domains of the healthy ageing model} A healthy ageing model was developed based on the WHO concept of healthy ageing [14]. Three components were considered: a) the intrinsic capacity, referring to the physical and mental health, b) the social and political environment, and c) the interaction of the older adult with the environment. To determine the intrinsic capacity, six domains were considered: 1) physiological and metabolic health, 2) geriatric syndromes, 3) risk factors, 4) physical capacity, 5) cognitive capacity, and 6) psychological wellbeing (Fig. 1). The physiological and metabolic health domain considered whether the individual has/had cancer, or has diabetes, hypertension or other chronic diseases, but they are under treatment or do not limit the functional status of the older person. The geriatric syndromes domain includes the absence of urinary and fecal incontinence, the number of falls and the presence of polypharmacy. In the risk factors domain we included measurements for cardiovascular risk, consumption of alcohol, tobacco, and physical activity. The physical capacity domain included compliance with activities of daily living, and a self-reported assessment of mobility, while the cognitive ability domain involved an assessment of dementia or cognitive impairment. The absence of physical, sexual, and psychological abuse, as well as absence of depression, where included in the psychological well-being domain.

The social and political environment component considered two domains: 1 ) the social welfare domain, which incorporated the social situation data as well as the presence of negligence or economic violence, and 2) the political environment domain, which measured if the older

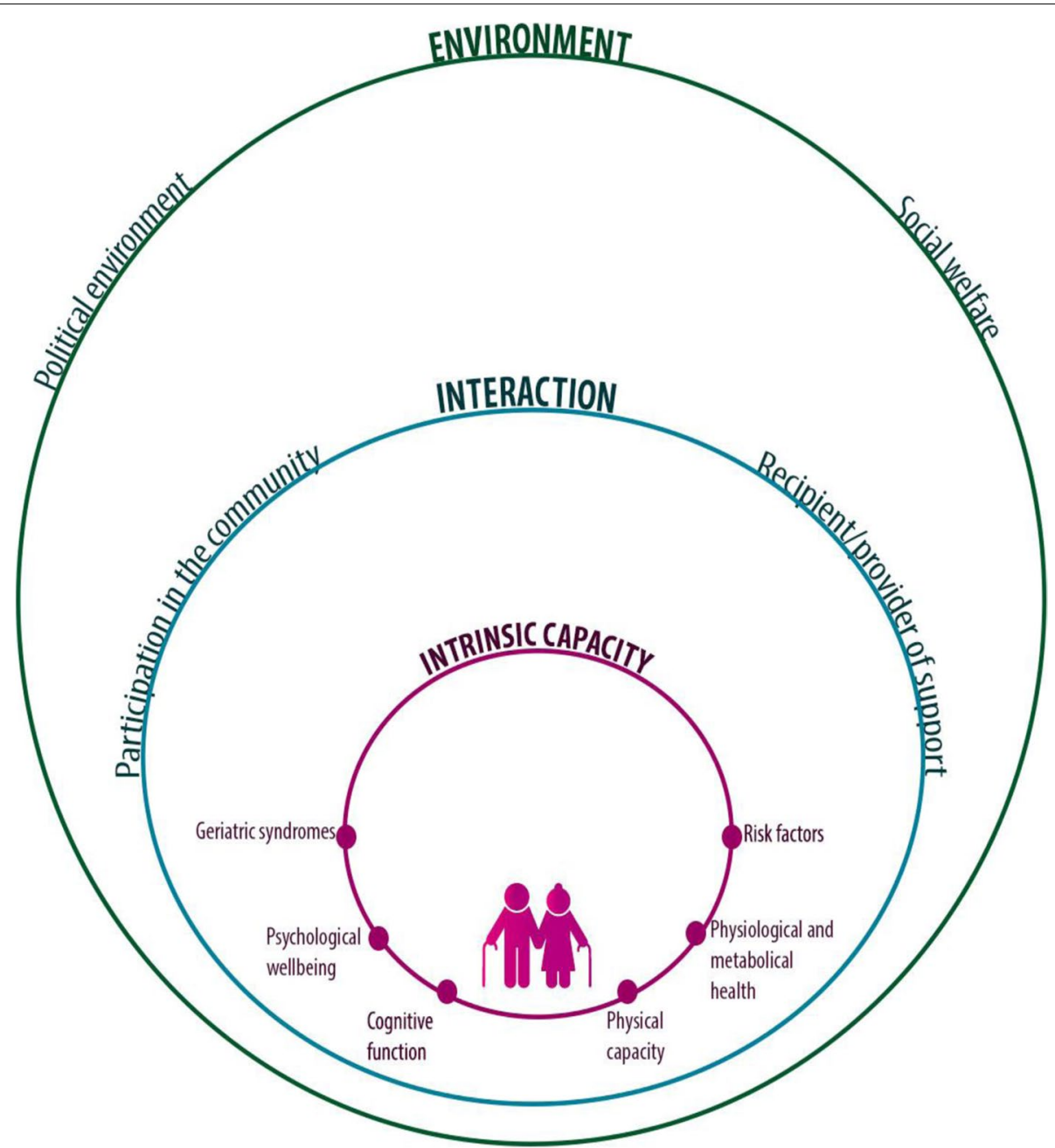

Fig. 1 Multimensional model of healthy ageing. The graph summarizes the components of the proposed multidimensional model: a intrinsic capacity [in red], b social and political environment [in green] and c interaction of the older adult with the environment [in blue], which determine the functional capacity of the elderly 
person had access to social security, health services and support from different institutions.

The component of interaction of the older adult with the environment involved the following domains: 1) participation of the older adult in the community, and 2) support provided by them and/or received from children, siblings and other family members or friends.

For each of the domains, criteria were established based on prior knowledge [5, 17-29], to conform two groups: a healthy group and a less healthy group (Table 1).

\section{Statistical analysis}

Based on the proposed theoretical model (Table 1), variables from the SABE survey were selected using the experience of previous studies focused on determining the prevalence of healthy ageing, as well as the expertise of the researchers $[4,12]$. From these variables, two theoretical groups were defined a priori: a healthy ageing group and a less healthy ageing group (Additional file 1). A two-stage cluster subdivision into intra-domain categories was performed according to compliance with the theoretical model, where the highest number reflects a better health status with respect to each domain, being 10 the highest score. Then, using a two-stage cluster categorization process, people were grouped into two clusters according to the similarity of their inter-domain categories. A radar graph was designed with the means of the domains for each cluster. It showed better scores for cluster 1 (healthy ageing group) than for cluster 2 (less healthy ageing group) ( $p$ value $<0.05)$, except in the risk factors domain, where a significant mean difference was not found (Fig. 2).

Finally, a bivariate logistic regression for complex samples, with an expansion factor available at the SABE dataset, was performed with the dependent variable of being part of the healthy ageing group. Then, with the significant variables $(p<0.05)$, a multivariate logistic regression for complex samples was performed. Explanatory variables were age, sex, area of residence, level of education, perceived health status, perceived life satisfaction, and poverty by income level. Statistical programs STATA ${ }^{\circledR}$ version 15.1 , and SPSS $^{\circledR}$ from IBM ${ }^{\circledR}$ version 25 were used for the statistical analysis.

\section{Results}

In the analyzed data, $56.65 \%$ were women and $43.35 \%$ men. More than half of the individuals were in the range of 65 to 74 years old (58.47\%). Complete information on the demographic characteristics of the sample is detailed in Table 2.

According to previously established criteria and cluster analysis, $53.15 \%$ of the sample was grouped into the healthy ageing group, and $46.85 \%$ corresponded to the less healthy ageing group. Table 3 describes the characteristics of these groups. The healthy ageing group showed a higher proportion of men than women $(60.74 \%$ vs $47.54 \%$, respectively), younger older adults $(57.41 \%$ between 65 to 74 vs $31.18 \%$ of 85 years old and older), living in urban areas (55.74\%) rather than in rural areas (47.47\%), mestizos (56\% vs $35 \%$ of indigenous) and older adults with higher education $(89.62 \%$ with college vs 41.07\% without formal education). Regarding perceived health status, $91.46 \%$ of older adults, who considered their health as excellent, and the $58.62 \%$ who were satisfied with their life, were in the healthy ageing group. In this group, $61.7 \%$ of the older adults were not poor.

Table 4 shows the results of the bivariate and multivariate analysis for healthy ageing group. Women were less likely to belong to the healthy ageing group, compared to men (OR $0.58,95 \%$ CI $0.46-0.74$ ), this association remained significant in the multivariate analysis (OR $0.69,95 \%$ CI $0.48-0.93)$. With regard to age, the group over 85 years was less likely to be in the healthy ageing group compared to people between 65 to 74 years (OR $0.33,95 \%$ CI $0.21-0.55$ ); this association remained significant in the multivariate analysis (OR 0.24, 95\% CI 0.14-0.41). An older adult living in rural areas was less likely to be in the healthy ageing group (OR $0.71,95 \% \mathrm{CI}$ 0.54-0.95); this association lost significance in the multivariate analysis. Older adults with secondary education or higher had 2.61 times the probability of being in the healthy ageing group (95\% CI 1.59-4.31), compared with primary education, and this association remained significant in the multivariate analysis (OR 2.22, 95\% CI 1.16-4.23). Older adults who considered their health as excellent had a greater probability of being in the healthy ageing group, compared to those who considered their health as poor (OR 28.49, 95\% CI 3.62-224.02). Those who were not satisfied with their lives were less likely to be in the healthy ageing group (OR 0.23, 95\% CI 0.170.34 ). Older adults within the limits of poverty were less likely to be in the healthy ageing group (OR 0.44, 95\% CI $0.343-0.564)$. These variables maintained their significant association in the multivariate analysis (OR 14.39, 95\% CI 2.92-70.82; OR 0.30, 95\% CI 0.19-0.49; OR 0.61 95\% CI 0.42-0.89) (Table 4).

\section{Discussion}

The interest in demonstrating that the ageing process is multidimensional concept is not a novel concern. By using different conceptualizations, many researchers have tried to describe the differences among those who age in better conditions and those who do not. The differences found by McLaughling, Jette and Connell [12] and Rodriguez-Laso and colleagues [4] in the prevalence of healthy ageing in the United States and Spanish 


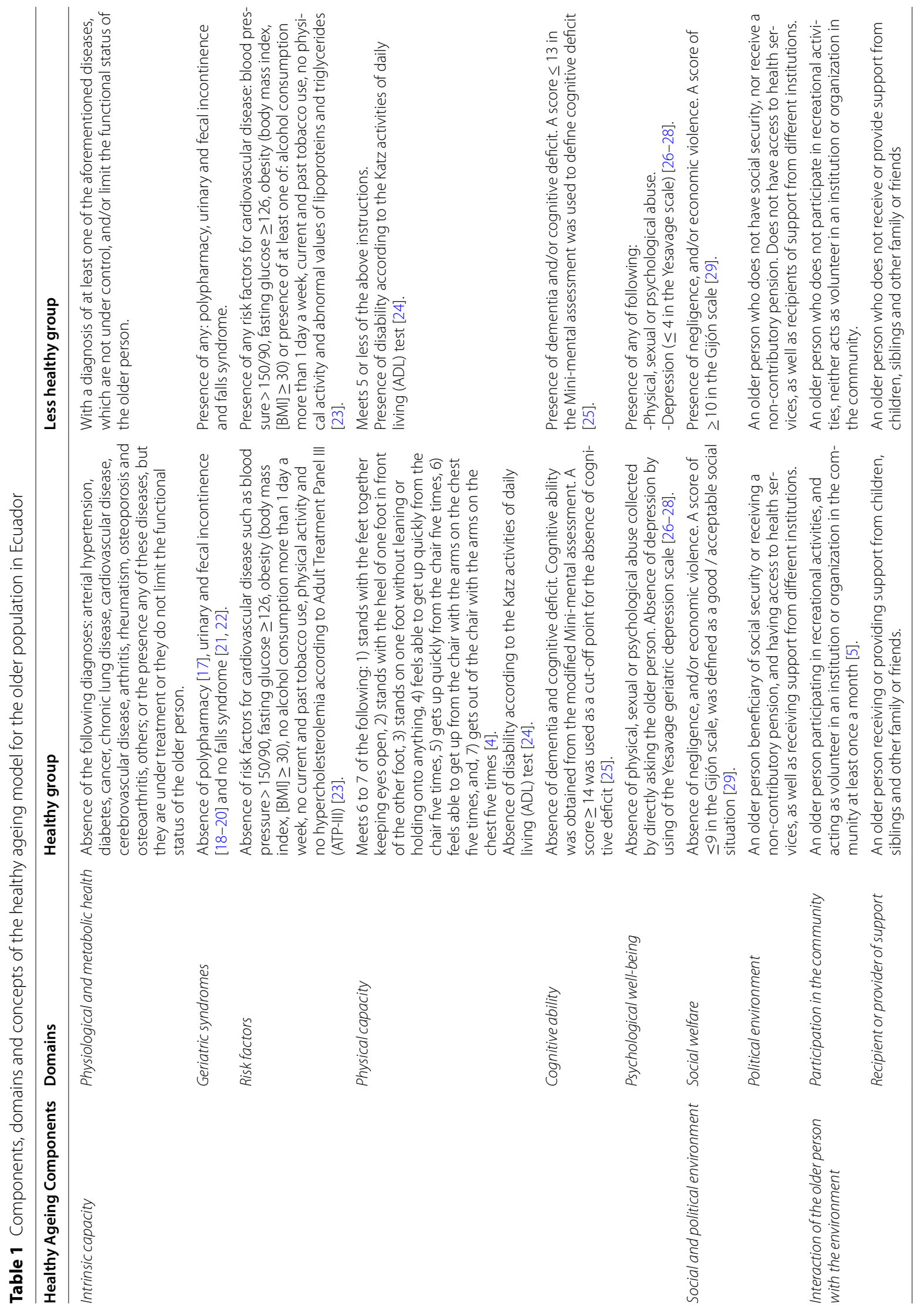




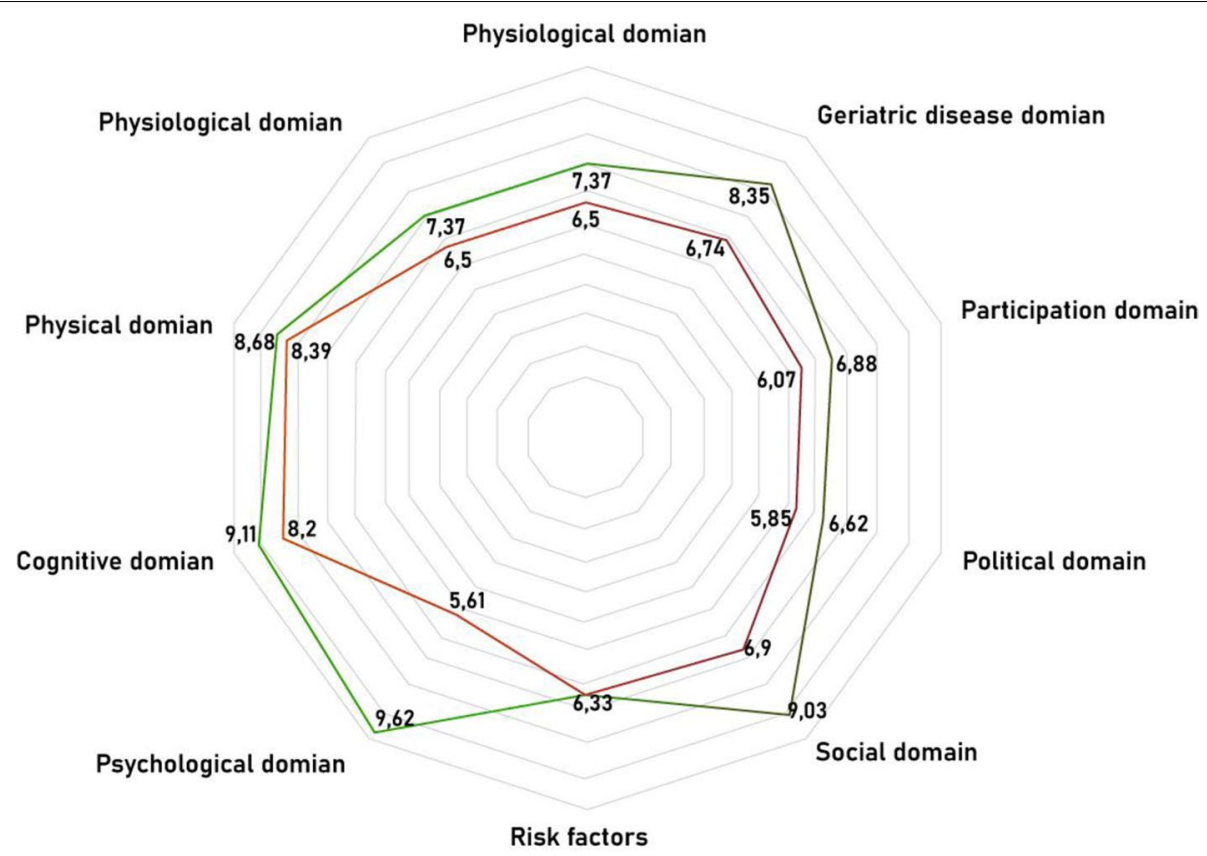

Mcluster 1 - Healthy ageing Mcluster 2- Less healthy ageing

Fig. 2 Radar chart showing two clusters with domains of the healthy ageing model. The graph presents two clusters: cluster 1 - "the healthy ageing group", and cluster 2 - "the less healthy group". The number represents the health status of each domain, the closer it is to 10, the better health status according to each domain

population, respectively, highlighted the need to use a more comprehensive criteria to identify the older population who is ageing in a better condition [14].

The present study contributes with a novel multidimensional model to assess the healthy ageing, based on the WHO concept, using a less rigorous definition that incorporates the role of the environment and the interaction of the older adult with it [14]. This comprehensive model breaks the paradigm that being healthy is equal to the absence of physical illness.

According to this model, in 2010, more than half (53.15\%) of the population over 65 years old belonged to the group of healthy ageing in Ecuador. This result differs from the data reported in the United States and Spain [4, 12]. This can be explained partly due to the sociodemographic differences of the older adults included in the different studies, but particularly by the multidimensional healthy ageing model applied in the present investigation. In our model, the intrinsic capacity of an older person with a healthy ageing was not limited to the absence of a disease or risk factors. As previous studies have shown that, despite physical limitations and structural obstacles, older people can be considered successful or active, given the compensation process they go through as they age $[6$, $10]$.
An interesting finding after the two-stage cluster analysis is the similarity of the two groups, healthy and less healthy, in the risk factors domain. This behavior could reinforce the idea that the ageing process and its trajectory does not only depend on the deterioration of the intrinsic capacity of the individual, but also on the environment where the person resides. Previous research has demonstrated that certain risk factors such as: obesity, sedentary lifestyle, smoking, alcohol consumption, have a great impact on how a person ages; but other elements of the environment, including demographic, epidemiological geographical, or economic situation, could affect the ageing trajectory too $[13,30]$.

In this study, women were less likely to belong to the healthy ageing group compared to men. This could be explained due to the association described between high levels of multimorbidity and female sex, where older women show a worse health status when compared to men of the same age [31]. Yet, other authors have pointed out that this association is more linked to age than sex, since it has been seen that after the age of 80 the differences in health status by sex are reduced $[6,30]$. In this study, the association between less healthy and female sex was maintained after adjusting for age and other 
Table 2 Demographic and socio-economic characteristics, older adults included in the study. National SABE-Ecuador survey, 2010-2011

\begin{tabular}{|c|c|c|}
\hline Variable & Frecuency $\left(\mathrm{n}^{\circ}\right)$ & $\begin{array}{l}\text { Relative } \\
\text { Frequency } \\
(\%)\end{array}$ \\
\hline \multicolumn{3}{|l|}{ Gender } \\
\hline Woman & 508,876 & 56.66 \\
\hline Man & 387,285 & 43.12 \\
\hline Missing values & 1991 & 0.22 \\
\hline Age & 1991 & 0.22 \\
\hline 65-74years & 475,053 & 52.89 \\
\hline $75-84$ years & 261,416 & 29.11 \\
\hline 85 years or more & 76,046 & 8.47 \\
\hline Missing values & 85,637 & 9.53 \\
\hline \multicolumn{3}{|l|}{ Area } \\
\hline Urban & 584,700 & 65.1 \\
\hline Rural & 313,452 & 34.9 \\
\hline Missing values & 0 & 0 \\
\hline \multicolumn{3}{|c|}{ Ethnic self-identification } \\
\hline Mestizo $^{\mathrm{a}}$ & 575,297 & 64.05 \\
\hline White & 118,342 & 13.18 \\
\hline Indigenous & 93,643 & 10.43 \\
\hline Mulatto ${ }^{b}$ & 30,569 & 3.4 \\
\hline Afro ecuadorian & 30,171 & 3.36 \\
\hline Other & 12,600 & 1.4 \\
\hline Missing values & 37,529 & 4.18 \\
\hline \multicolumn{3}{|l|}{ Level of education } \\
\hline None & 15,181 & 1.69 \\
\hline Literacy center & 19,632 & 2.19 \\
\hline Kinder Garden & 2745 & 0.31 \\
\hline Primary & 503,793 & 56.09 \\
\hline High school & 82,704 & 9.21 \\
\hline College & 23,778 & 2.65 \\
\hline Post graduate & 2254 & 0.25 \\
\hline Missing values & 248,065 & 27.62 \\
\hline
\end{tabular}

a Mestizos = ethnic group born from the cross between Europeans, indigenous and Africans during the colonial era. It is a hegemonic category that includes other socio-racial identities, including indigenous people themselves and black people with all their derivations

${ }^{\mathrm{b}}$ Mulatto = relating to black people of African descent mixed socio-racially with white or mestizo populations

variables, which points to gender inequalities in the way of ageing.

Age, educational level and economic status were also associated with healthy ageing. As a person ages, their risk for suffering from multiple chronic conditions and disability increases, impacting negatively on their intrinsic capacity and consequently in their functional capacity [32-34]. Therefore, it was not surprising that in our study individuals of 85 years old or more showed lower odds of experiencing a healthy ageing. On the other hand, having a higher educational level increased the odds of being in the healthy ageing group. These results coincide with previous studies that have shown the positive effect of education in older adults to access to health services, adhere to medical treatments and understand health issues, which in turn contributes to improve their quality of life [35-41].

According to our data, older adults in the worst economic situation were less likely to be in the healthy ageing group, making them a highly vulnerable group. There is vast evidence of the association between a low socioeconomic level and poorer physical and mental health in older adults, as a consequence of exposure to a greater number of risk factors, anxiety, and less access to health services from younger ages [40-42].

In the present study, no significant difference was found between living in an urban or rural area. The combination of an unfavorable external environment for the older population, as well as personal poverty increase their risk of having a poor physical, psychological and mental health status, social isolation, and higher risk of death $[43,44]$. For this reason, the limitations of the environment, and not simply the place of residence, could be a more important factor to consider when defining whether an older person is ageing in a healthy way or not.

Self-perceived health status and life satisfaction were also associated with healthy ageing. In this study, most of the older adults who had a positive perception of their health were categorized in the healthy ageing group. This may be because the healthy ageing group includes people with the best intrinsic capacity and an environment that meets their needs. However, this could also be explained in terms of the "disability paradox"; where in presence of severe disability, a person reports high quality of life, due to their ability to adapt to their condition, finding a balance between their intrinsic capacity and the environment $[45,46]$.

We have some limitations in this study. SABE was conducted 11 years ago, so the reported findings might not reflect the current situation of the Ecuadorian older population. In the last 11 years, Ecuador has experienced important political and socioeconomical changes that could have modified the situation of the older population. However, this is the only survey carried out in the older adult population on a national scale. There is no recent or updated information on the situation of the elderly in Ecuador; therefore it was not possible to perform an analysis of the trend of healthy ageing over time. In the same way, it was not possible to extrapolate the data obtained to the current population, nor to propose a prevalence of healthy ageing, under current conditions. This would require data collection over time, which would be an important recommendation for future studies. 
Table 3 Socio-demographic characteristics for healthy and less healthy ageing. National Base SABE-Ecuador, 2010-2011

\begin{tabular}{|c|c|c|c|c|}
\hline Variable & Healthy ageing $(n)$ & Relative frequency (\%) & Less healthy ageing $(n)$ & $\begin{array}{l}\text { Relative } \\
\text { frequency } \\
(\%)\end{array}$ \\
\hline \multicolumn{5}{|l|}{ Gender } \\
\hline Man & 200,574 & 60.74 & 129,623 & 39.26 \\
\hline Woman & 205,012 & 47.54 & 226,230 & 52.46 \\
\hline \multicolumn{5}{|l|}{ Age } \\
\hline 65-74years & 239,846 & 57.41 & 177,899 & 42.59 \\
\hline $75-84$ years & 117,437 & 51.29 & 111,549 & 48.71 \\
\hline 85 years or more & 16,204 & 31.18 & 35,773 & 68.82 \\
\hline \multicolumn{5}{|l|}{ Area } \\
\hline Urban & 292,002 & 55.74 & 231,828 & 44.26 \\
\hline Rural & 113,750 & 47.47 & 125,850 & 52.53 \\
\hline \multicolumn{5}{|l|}{ Ethnicity } \\
\hline Mestizo & 280,883 & 56.00 & 220,681 & 44.00 \\
\hline White & 53,999 & 51.47 & 50,923 & 48.53 \\
\hline Indigenous & 23,955 & 35.02 & 44,451 & 64.98 \\
\hline Afro ecuadorian & 15,452 & 64.69 & 8436 & 35.31 \\
\hline Mulatto & 14,900 & 56.64 & 11,408 & 43.36 \\
\hline Other & 4367 & 38.50 & 6977 & 61.50 \\
\hline \multicolumn{5}{|l|}{ Level of eduction } \\
\hline None & 4903 & 41.07 & 7036 & 58.93 \\
\hline Literacy & 4522 & 26.01 & 12,862 & 73.99 \\
\hline Kinder garden & 1212 & 44.15 & 1533 & 55.85 \\
\hline Primary & 240,836 & 54.82 & 198,513 & 45.18 \\
\hline High school & 58,032 & 76.03 & 18,293 & 23.97 \\
\hline Bachelor & 1717 & 100.00 & 0 & 0.00 \\
\hline College & 18,143 & 89.62 & 2102 & 10.38 \\
\hline Post Graduate & 2254 & 100.00 & 0 & 0.00 \\
\hline \multicolumn{5}{|c|}{ How do you consider your health } \\
\hline Excellent & 7180 & 91.46 & 670 & 8.54 \\
\hline Very good & 14,484 & 76.54 & 4440 & 23.46 \\
\hline Good & 117,367 & 73.79 & 41,697 & 26.21 \\
\hline Regular & 224,147 & 53.24 & 196,861 & 46.76 \\
\hline Bad & 42,574 & 27.33 & 113,200 & 72.67 \\
\hline \multicolumn{5}{|c|}{ Are you satisfied with your life } \\
\hline Yes & 373,827 & 58.62 & 263,883 & 41.38 \\
\hline No & 30,986 & 25.18 & 92,084 & 74.82 \\
\hline \multicolumn{5}{|l|}{ Income poverty ${ }^{a}$} \\
\hline No & 272,076 & 61.67 & 169,120 & 38.33 \\
\hline yes & 133,676 & 41.48 & 188,558 & 58.52 \\
\hline
\end{tabular}

${ }^{\mathrm{a}}$ Income poverty $=$ income less than USD 1.90 per day

Additionally, the variables included in the domains were restricted to those available in the national survey. Despite the richness of the data, we did not have more in-depth information on laboratory or clinical tests. It is possible that some data contained memory and information biases, particularly data that required a clinical diagnosis, as in the case of previous diseases. On the other hand, due to the characteristics of the study, it was not possible to make cause-effect inferences. Finally, the absence of a unified and operational definition of healthy ageing makes a direct comparison between studies impossible.

The main strength of this study is the design of a multidimensional model of healthy ageing, for which 
Table 4 Association between healthy ageing group with determinants. SABE-Ecuador national base, 2010-2011

\begin{tabular}{|c|c|c|c|c|c|c|}
\hline \multirow[b]{2}{*}{ Variable } & \multicolumn{3}{|c|}{ Bivariate analysis } & \multicolumn{3}{|c|}{ Multivariate analysis } \\
\hline & Odds Ratio & $95 \%$ IC & $p$-Value & Odds Ratio & $95 \%$ IC & $p$-Value \\
\hline \multicolumn{7}{|l|}{ Gender } \\
\hline Man & Reference & & & Reference & & \\
\hline Woman & 0.58 & $0.46-0.78$ & $0.00^{* *}$ & 0.69 & $0.48-0.93$ & $0.01^{*}$ \\
\hline \multicolumn{7}{|l|}{ Age } \\
\hline 65-74years & Reference & & & Reference & & \\
\hline $75-84$ years & 0.78 & $0.58-1.05$ & 0.09 & 0.88 & $0.59-1.30$ & 0.53 \\
\hline 85 years or more & 0.33 & $0.21-0.55$ & $0.00^{* *}$ & 0.24 & $0.14-0.42$ & $0.00^{* *}$ \\
\hline \multicolumn{7}{|l|}{ Area } \\
\hline Urban & Reference & & & Reference & & \\
\hline Rural & 0.71 & $0.54-0.95$ & $0.02^{*}$ & 0.98 & $0.67-1.47$ & 0.92 \\
\hline \multicolumn{7}{|l|}{ Ethnicity } \\
\hline Mestizo ${ }^{a}$ & Reference & & & Reference & & \\
\hline Indigenous & 1.43 & $0.72-2.86$ & 0.29 & 1.06 & $0.41-2.77$ & 0.91 \\
\hline Afro ecuadorian & 1.02 & $0.48-2.16$ & 0.95 & 1.28 & $0.47-3.51$ & 0.63 \\
\hline Mulatto & 0.83 & $0.55-0.13$ & 0.39 & 0.63 & $0.39-1.01$ & 0.06 \\
\hline White & 0.42 & $0.27-0.67$ & $0.00^{* *}$ & 0.69 & $0.34-1.39$ & 0.29 \\
\hline Other & 0.49 & $0.19-1.27$ & 0.14 & 0.29 & $0.08-1.04$ & 0.06 \\
\hline \multicolumn{7}{|l|}{ Level of education } \\
\hline Primary & Reference & & & Reference & & \\
\hline None & 0.57 & $0.19-1.72$ & 0.32 & 0.49 & $0.14-1.65$ & 0.25 \\
\hline Literacy & 0.28 & $0.11-0.76$ & 0.01 & 0.28 & $0.10-0.78$ & 0.02 \\
\hline Kinder gander/ primary & 0.65 & $0.06-7.10$ & 0.72 & 0.66 & $0.06-6.71$ & 0.73 \\
\hline High school & 2.61 & $1.57-4.31$ & $0.00^{* *}$ & 2.22 & $1.16-4.23$ & $0.02^{*}$ \\
\hline College / post graduate & 7.11 & $2.16-23.39$ & $0.00^{* *}$ & 2.85 & $0.79-10.19$ & 0.11 \\
\hline \multicolumn{7}{|c|}{ How do you consider your health } \\
\hline Bad & Reference & & & Reference & & \\
\hline Excellent & 28.49 & $3.62-224.03$ & $0.00^{* *}$ & 14.39 & $2.92-70.83$ & $0.00^{* *}$ \\
\hline Very good & 8.67 & $3.43-21.93$ & $0.00^{* *}$ & 7.62 & $1.64-35.44$ & $0.01^{*}$ \\
\hline Good & 7.48 & $5.01-11.17$ & $0.00^{* *}$ & 6.61 & $3.76-11.63$ & $0.00^{* *}$ \\
\hline Regular & 3.02 & $2.18-4.19$ & $0.00^{* *}$ & 3.76 & $2.50-5.67$ & $0.00^{* *}$ \\
\hline \multicolumn{7}{|l|}{ Are you satisfied with your life } \\
\hline Yes & Reference & & & Reference & & \\
\hline No & 0.23 & $0.17-0.34$ & $0.00^{* *}$ & 0.3 & $0.18-0.49$ & $0.00^{* *}$ \\
\hline \multicolumn{7}{|l|}{ Income poverty ${ }^{a}$} \\
\hline No & Reference & & & Reference & & \\
\hline $\mathrm{Si}$ & 0.44 & $0.34-0.56$ & $0.00^{* *}$ & 0.61 & $0.42-0.89$ & $0.01^{*}$ \\
\hline
\end{tabular}

${ }^{a}$ Income poverty $=$ income less than USD 1.90 per day

*Value $p$ significant $<0.05$; **Value $p$ significantt $<0.01$

secondary data from a national survey was used. The proposed model offers a holistic approach to healthy ageing, which includes components such as the environment and the interaction of the older adult, which have not previously been addressed. This model contributes not only to understanding the heterogeneity of ageing, but also to identifying the group of older adults who need to be prioritized in public policies. The evidence suggests the importance of healthy ageing policies focused on improving socioeconomic conditions and reducing gender inequalities.

\section{Conclusion}

The model of healthy ageing addresses multidimensional variables in nine domains, which are summarized in three components: the intrinsic capacity, referring to 
the physical and mental health, the social and political environment, and the interaction of the older adults with the environment. This model conceptualizes healthy ageing in a comprehensive way, discriminating between the healthy group and the less healthy group. By using this model, it was identified that gender and economic situation seem to play an important role on heathy ageing of the Ecuadorian population. Public policies are necessary to promote healthy ageing, especially focused on improving socioeconomic conditions and gender equity.

\section{Abbreviations}

ADL: Activities of daily living; ATP-III: Adult Treatment Panel III; BMI: Body mass index; INEC: National Institute for Statistics and Census; MIES: Ministry of Economic and Social Inclusion; OR: Odds ratio; WHO: World Health Organization; 95\% Cl: 95\% Confidence interval.

\section{Supplementary Information}

The online version contains supplementary material available at https://doi. org/10.1186/s12877-021-02548-5.

Additional file 1 Theoretical model used for the classification into healthy and less healthy ageing groups.

\section{Acknowledgements}

Not applicable.

\section{Authors' contributions}

MR proposed the study and initial design. MM contributed to the theoretical conceptualization of the model. JC performed the statistical analysis. JV and PB contributed to the definition of variables and geriatric concepts. All the authors participated in the final design of the proposed ageing model. MM and MR wrote the main manuscript text, JC, JV and PB reviewed the manuscript and made important contributions. The authors read and approved the final manuscript.

\section{Funding}

This research was funded by the Pontificia Universidad Católica del Ecuador, project code 082-UIO-2019.

\section{Availability of data and materials \\ The database for this study is publicly available at Instituto Nacional de Estadísticas y Censos (INEC), Secretaría Nacional de Planificación y Desarrollo (SENPLADES). Encuesta de Salud, Bienestar y Envejecimiento - SABE 2009. 2010. https://anda.inec.gob.ec/anda/index.php/catalog/292 [16].}

\section{Declarations}

\section{Ethics approval and consent to participate}

Secondary database study does not require approval.

\section{Consent for publication}

Not applicable.

\section{Competing interests}

The authors declare that they have no competing interests.

\section{Author details}

${ }^{1}$ Pontificia Universidad Católica del Ecuador, Facultad de Medicina, Instituto de Salud Pública, Quito, Ecuador. ${ }^{2}$ Department of Public Health, Institute of Nursing Science, University of Basel, Basel, Switzerland. ${ }^{3}$ Department of Public Health and Primary Care, Patient Related and Public Health Research, KU Leuven, Doctoral School of Biomedical Sciences, Leuven, Belgium. ${ }^{4}$ Pontificia
Universidad Católica del Ecuador, Facultad de Medicina, Posgrado de Geriatría y Gerontología, Quito, Ecuador.

Received: 27 February 2021 Accepted: 5 October 2021

Published online: 01 November 2021

\section{References}

1. United Nations, Department of Economic and Social Affairs, Population Division. World Population Ageing 2017—Highlights. 2017. https://www. un.org/en/development/desa/population/publications/pdf/ageing/ WPA2017_Highlights.pdf. Accessed 5 Jan 2021.

2. Johnston MC, Crilly M, Black C, Prescott GJ, Mercer SW. Defining and measuring multimorbidity: a systematic review of systematic reviews. Eur J Pub Health. 2019;29(1):182-9.

3. National Center for Chronic Disease Prevention and Health Promotion. The Power of Prevention: Chronic Disease. The Public Health Challenge of the 21st Century [Data set]. American Psychological Association. 2009. https://doi.org/10.1037/e581002012-001. Accessed 8 Jan 2021.

4. Rodriguez-Laso A, McLaughlin SJ, Urdaneta E, Yanguas J. Defining and estimating healthy aging in Spain: a cross-sectional study. The Gerontologist. 2018;58(2):388-98.

5. Bowling A. The concepts of successful and positive ageing. Fam Pract. 1993;10(4):449-53.

6. Pruchno R. Successful aging: contentious past, productive future. Gerontologist. 2015;55(1):1-4.

7. Rowe JW, Kahn RL. Successful aging. The Gerontologist. 1997;37(4):433-40.

8. Martinson M, Berridge C. Successful aging and its discontents: a systematic review of the social gerontology literature. The Gerontologist. 2015;55(1):58-69

9. Foster L, Walker A. Active and successful aging: a European policy perspective. The Gerontologist. 2015;55(1):83-90.

10. Paúl C, Ribeiro O, Teixeira L. Active Ageing: An Empirical Approach to the WHO Model. Curr Gerontol Geriatr Res. 2012;2012:382972.

11. Bélanger $E$, Ahmed T, Filiatrault J, Yu HT, Zunzunegui MV. An empirical comparison of different models of active aging in Canada: the international mobility in aging study. The Gerontologist. 2017;57(2):197-205.

12. McLaughlin SJ, Jette AM, Connell CM. An examination of healthy aging across a conceptual continuum: prevalence estimates, demographic patterns, and validity. J Gerontol Ser A. 2012;67(7):783-9.

13. Dieteren CM, Samson LD, Schipper M, van Exel J, Brouwer WBF, Verschuren WMM, et al. The healthy aging index analyzed over 15 years in the general population: the Doetinchem cohort study. Prev Med. 2020;139:106193.

14. World Health Organization (WHO). Informe mundial sobre el envejecimiento y la salud:WHO Press; 2015. http://apps.who.int/iris/bitstream/ handle/10665/186466/9789240694873_spa.pdf?sequence=1. Accessed 5 Jan 2021

15. Freire W, Rojas E, Pazmiño L, Fornasini M, Tito S, Buendía P, et al. Encuesta Nacional de Salud, Bienestar y Envejecimiento. SABE I, Ecuador, 20092010. Quito: Ministerio de Inclusión Económica y Social - Programa Aliméntate Ecuador; 2010.

16. Instituto Nacional de Estadísticas y Censos (INEC), Secretaría Nacional de Planificación y Desarrollo (SENPLADES). Encuesta de Salud, Bienestar y Envejecimiento - SABE 2009. 2010. https://anda.inec.gob.ec/anda/index. php/catalog/292/study-description. Accessed 8 June 2021.

17. Masnoon N, Shakib S, Kalisch-Ellett L, Caughey GE. What is polypharmacy? A systematic review of definitions. BMC Geriatr. 2017;17(1):1-10.

18. Chong EC, Khan AA, Anger JT. The financial burden of stress urinary incontinence among women in the United States. Curr Urol Rep. 2011;12(5):358-62.

19. Ekelund P, Grimby A, Milsom I. Urinary incontinence. Social and financial costs high. BMJ. 1993;306(6888):1344.

20. Kessler M, Facchini LA, Soares MU, Nunes BP, França SM, Thumé E. Prevalence of urinary incontinence among the elderly and relationship with physical and mental health indicators. Rev Bras Geriatria Gerontol. 2018;21(4):397-407.

21. Burns ER, Stevens JA, Lee R. The direct costs of fatal and non-fatal falls among older adults_-United States. J Saf Res. 2016;58:99-103. 
22. Gazibara T, Kurtagic I, Kisic-Tepavcevic D, Nurkovic S, Kovacevic N, Gazibara $T$, et al. Falls, risk factors and fear of falling among persons older than 65 years of age. Psychogeriatrics. 2017;17(4):215-23.

23. Cleeman J, ATP III. Guidelines at-A-glance quick desk reference; 2001.

24. Katz S, Downs TD, Cash HR, Grotz RC. Progress in development of the index of ADL. Gerontologist. 1970;10:20-30.

25. Folstein MF, Folstein SE, McHugh PR. "Mini-mental state": a practical method for grading the cognitive state of patients for the clinician. J Psychiatr Res. 1975;12(3):189-98.

26. Anderson DN. Treating depression in old age: the reasons to be positive. Age Ageing. 2001;30(1):13-7.

27. Yesavage JA, Sheikh JI. Geriatric depression scale (GDS): recent evidence and development of a shorter version. Clin Gerontol. 1986:5(1-2):165-73.

28. Zis P, Daskalaki A, Bountouni I, Sykioti P, Varrassi G, Paladini A. Depression and chronic pain in the elderly: links and management challenges. Clin Interv Aging. 2017;12:709-20.

29. Alarcón-Alarcón T, González-Montalvo Jl. La Escala Socio-Familiar de Gijón, instrumento útil en el hospital general. Rev Española Geriatría Gerontol. 1998;33(3):175-9.

30. Wong R, Ofstedal MB, Yount K, Agree EM. Unhealthy lifestyles among older adults: exploring transitions in Mexico and the US. Eur J Ageing. 2008;5(4):311.

31. Violan C, Foguet-Boreu Q, Flores-Mateo G, Salisbury C, Blom J, Freitag $M$, et al. Prevalence, determinants and patterns of multimorbidity in primary care: a systematic review of observational studies. PLoS One. 2014;9(7):e102149.

32. Hu RH, Hsiao FY, Chen LJ, Huang PT, Hsu WWY. Increasing age- and gender-specific burden and complexity of multimorbidity in Taiwan, 2003-2013: a cross-sectional study based on nationwide claims data. BMJ Open. 2019;9(6):e028333.

33. Roberts KC, Rao DP, Bennett TL, Loukine L, Jayaraman GC. Prevalence and patterns of chronic disease multimorbidity and associated determinants in Canada. Health Promot Chron Dis Prev Canada Rese Policy Pract. 2015;35(6):87-94

34. Barnett K, Mercer SW, Norbury M, Watt G, Wyke S, Guthrie B. Epidemiology of multimorbidity and implications for health care, research, and medical education: a cross-sectional study. Lancet. 2012;380(9836):37-43.

35. Baker DW, Wolf MS, Feinglass J, Thompson JA, Gazmararian JA, Huang J. Health literacy and mortality among elderly persons. Arch Intern Med. 2007:167(14):1503-9.
36. Bennett IM, Chen J, Soroui JS, White S. The contribution of health literacy to disparities in self-rated health status and preventive health behaviors in older adults. Ann Fam Med. 2009;7(3):204-11.

37. Cho YI, Lee SYD, Arozullah AM, Crittenden KS. Effects of health literacy on health status and health service utilization amongst the elderly. Soc Sci Med. 2008;66(8):1809-16.

38. Sudore RL, Mehta KM, Simonsick EM, Harris TB, Newman AB, Satterfield $S$, et al. Limited literacy in older people and disparities in health and healthcare access. J Am Geriatr Soc. 2006;54(5):770-6.

39. Toci E, Burazeri G, Jerliu N, Sørensen K, Ramadani N, Hysa B, et al. Health literacy, self-perceived health and self-reported chronic morbidity among older people in Kosovo. Health Promot Int. 2015;30(3):667-74.

40. Brinda EM, Rajkumar AP, Attermann J, Gerdtham UG, Enemark U, Jacob KS. Health, social, and economic variables associated with depression among older people in low and middle income countries: World Health Organization study on global AGEing and adult health. Am J Geriatr Psychiatry. 2016;24(12):1196-208.

41. Gama D, Colombo D. Closing the gap in a generation: health equity through action on the social determinants of health. Final report of the commission on social determinants of health. Rev Direito Sanitário. 2010;10(3):253-66.

42. Vaalavuo M. Deterioration in health: what is the role of unemployment and poverty? Scand J Public Health. 2016;44(4):347-53.

43. Mahmood A, Chaudhury H, Michael YL, Campo M, Hay K, Sarte A. A photovoice documentation of the role of neighborhood physical and social environments in older adults' physical activity in two metropolitan areas in North America. Soc Sci Med. 2012;74(8):1180-92.

44. Zhang X, Dupre ME, Qiu L, Zhou W, Zhao Y, Gu D. Urban-rural differences in the association between access to healthcare and health outcomes among older adults in China. BMC Geriatr. 2017;17(1):1-11.

45. Albrecht GL, Devlieger PJ. The disability paradox: high quality of life against all odds. Soc Sci Med. 1999;48(8):977-88.

46. Kusumastuti S, Derks MGM, Tellier S, Di Nucci E, Lund R, Mortensen EL, et al. Successful ageing: a study of the literature using citation network analysis. Maturitas. 2016;93:4-12.

\section{Publisher's Note}

Springer Nature remains neutral with regard to jurisdictional claims in published maps and institutional affiliations.
Ready to submit your research? Choose BMC and benefit from:

- fast, convenient online submission

- thorough peer review by experienced researchers in your field

- rapid publication on acceptance

- support for research data, including large and complex data types

- gold Open Access which fosters wider collaboration and increased citations

- maximum visibility for your research: over $100 \mathrm{M}$ website views per year

At $\mathrm{BMC}$, research is always in progress.

Learn more biomedcentral.com/submissions 